\title{
NOTAS SOBRE LA COHESIÓN DE LA COMUNIDAD MORISCA MÁS ALLÁ DE SU EXPULSIÓN DE ESPAÑA
}

\author{
NOTES ON THE COHESION OF THE MORISCO \\ COMMUNITY BEYOND THE EXPULSION FROM SPAIN
}

\author{
LUIS F. BERnABÉ PONS \\ Universidad de Alicante
}

\begin{abstract}
Pese a que la expulsión de 1609 supuso para los moriscos una rápida desbandada de sus lugares de origen, algunos grupos de moriscos se encontraban preparados para afrontarla con más garantías. A través de la documentación, puede comprobarse cómo moriscos castellanos y granadinos lograron sacar mucho dinero de España con la colaboración de judeoconversos y aprovechándose de unas redes que ya parecen establecidas en Francia tiempo atrás. Mediante esas redes se logra que ciertos moriscos granadinos actúen como guías de su comunidad durante todo el tránsito fuera de España hasta su establecimiento en Túnez. Aunque las autoridades españolas cuentan con espías entre los moriscos, la alianza de estos granadinos con los cherifes tunecinos contribuirá al éxito de la implantación morisca en Túnez.
\end{abstract}

Palabras clave: Moriscos; expulsión; colaboración; espías; Francia; Túnez.
Despite the fact that the expulsion of 1609 meant for the Moriscos a sudden uprooting from their places of origin, some groups of Moriscos had prepared themselves for it. Through archival documents we know that Castilian and Granadan Moriscos managed to smuggle large amounts of money from Spain with the collaboration of converted Jews making use of certain networks that seem to have been previously established in France. Through these networks a number of Granadan Moriscos could act as guides for their community during the entire transfer from Spain up to its establishment in Tunis. Although the Spanish authorities had their spies among the Morisco communities, the allience between the Granadan and the Tunisian authorities would contribute to the succesful establishment of the Moriscos in Tunis.

Key words: Moriscos; Expulsion; Collaboration; Spies; France; Tunis.

\section{Introducción}

De lo mucho que ya se ha escrito en torno a los moriscos ${ }^{1}$, son quizá los años alrededor de la expulsión general que dio comienzo en 1609 los más imperfectamente conocidos a la hora de evaluar el comportamiento de esta comunidad. Tanto los años en los que agonizaba

${ }^{1}$ Introducción bibliográfica en Bernabé Pons, L.F., "Las emigraciones moriscas al Magreb: balance bibliográfico y perspectivas", en A.I. Planet y F. Ramos (coords.), Relaciones Hispano-Marroquies: Una Vecindad en Construcción, Madrid, 2006, 63-100. 
su presencia en España, como los que siguieron inmediatamente a su exilio forzoso se nos escapan en gran medida, quizá eclipsados por el poderoso hecho mismo de la expulsión. No me refiero, claro está, a cuestiones como la mecánica de la expulsión, el vaciamiento de los pueblos, los bienes moriscos o el primer destino de éstos, ejemplos que cuentan con buenos estudios, antiguos y modernos. Hago referencia ahora a que, por un lado, apenas sabemos de las maniobras de los moriscos en los años previos a la expulsión, de sus seguros temores y sus posibles salvaguardas ante la tragedia que se avecinaba; $y$, por otro lado, tampoco estamos muy duchos en los primeros movimientos de los moriscos una vez abandonan territorio hispano.

Ambos momentos son, sin embargo, de una especial importancia si se intenta calibrar en la medida de lo posible los eventuales comportamientos que, como grupo o grupos organizados, pudieron tener los moriscos ante una medida que a todos afectaba. No deja de ser hasta cierto punto llamativo el hecho de que esa cierta cohesión grupal, vecinal o familiar que ha sido invocada y analizada en muchos estudios sobre los moriscos en España ${ }^{2}$, parecería que se evaporase con la expulsión y volviera a condensarse más tarde, una vez asentados los moriscos principalmente en el norte de África. ¿Había acabado la expulsión con los lazos de solidaridad o de colaboración de los moriscos? ¿Existió una especie de «sálvese quien pueda» a la hora de salir de España que no hizo del éxodo morisco sino una suma de miles de aventuras individuales?

Quisiera contribuir a responder a estas preguntas planteando algunas formas de cohesión activa entre los moriscos más allá de España, y de cooperación entre los moriscos y los judeoconversos, llevadas a cabo alrededor del eje marcado por las medidas dispuestas a partir de 1609. Aunque evidentemente alguna de esas formas ya estaba en funcionamiento con anterioridad a la expulsión, fue con ocasión de ésta cuando fue explotada de forma plena, mostrando que algunos moriscos se habían adelantado a la medida del rey Felipe y habían preparado ya un buen viático para su travesía.

${ }^{2}$ Epalza, M. de, "Les morisques, vus à partir des communautés mudéjares précédentes", en Les Morisques et leur temps. Table Ronde Internationale. 4-7 juillet 1981, Paris, 1983, 31-41.

Al-Qanțara (AQ) XXIX 2, julio-diciembre 2008, pp. 307-332 ISSN 0211-3589 


\section{La expulsión: moriscos y judeoconversos}

El legajo 627 de la sección Estado del Archivo General de Simancas contiene entre sus páginas un documento encabezado por la leyenda «Auisos de los portugueses de quien se valieron los moriscos para sacar el dinero y joyas que tenían, dado por Lorenzo Suárez». Estos avisos consisten en la descripción física, vestimenta y posible localización de una serie de personas, así como el origen del dinero morisco que han sacado de España ${ }^{3}$. De esta forma, vemos desfilar a un Pedro Sánchez y a su hermano Juan Enríquez; a Gaspar Fernández Maricos y su hijo Simón Fernández, alias los «retorçidos»; a Gaspar Fernández Faya, que es quien ha manejado el dinero de los moriscos de Ávila, Madrid y Valladolid; a Antonio Enríquez Bueno y su padre Antonio Enríquez; a Alonso Gómez Reinoso y Luis de Zamora, que han sacado el dinero de Madrid y Guadalajara; a Juan, Pedro y Bartolomé López Téllez, que manejaron el dinero de Salamanca, Valladolid, Medina del Campo y Pastrana; y a Antonio Méndez Cardoso, Vicente Núñez y Luis de Fonseca, que pasaron el dinero «de los Galazes y otros moriscos de Burgos». Este Méndez Cardoso recién citado, además, se dedica, según el espía madrileño, a introducir gran cantidad de moneda falsa en el reino a partir del puerto de Deva, por lo que recomienda que se refuerce por parte de las autoridades la vigilancia en las fronteras.

Los siguientes documentos del legajo nos amplían y detallan la información que se suministraba en esta primera relación, a través del resumen de tres cartas del susodicho Lorenzo Suárez, fechadas en San Juan de Luz el 23 de febrero, 15 de junio y 2 de agosto de $1612^{4}$.

3 Véase como ejemplo Archivo General de Simancas (AGS), Estado, 627, s.p.: «Gaspar Fernández de Faya es un hombre lampiño de barua; la que tiene, rubia; feo de rostro, alto, dentimellado, las piernas algo delgadas, mal entalladas. Suele andar de camino con un vestido de paño de Segovia de color de capa de rey guarneçido al canto con un pasamano rosa seca y verdemar, y un jubón de raso verdemar guarneçido de canto en un pasamano rosa seca y un jubón de raso verdemar guarneçido destas colores. Y éste es el que a pagado gran cantidad de dinero de Ávila y Madrid, Valladolid y otras partes. Hazíale espadas Fernán Franco en Madrid, que biue a la subida de San Luis, y aquí le afianzaua Diego Gómez de Açeuedo, padre de Fernán Franco, y lo mismo Antonio Enrríquez Bueno», (puntuación y acentuación del texto son mías).

4 Transcritas parcialmente en García-Arenal, M. y Wiegers, G., Entre el Islam y Occidente. Vida de Samuel Pallache, judio de Fez, Madrid, 1999, 86-87; ibidem, Un hombre en tres mundos. Samuel Pallache, un judio marroqui en la Europa protestante y en la católica, Madrid 2007 (2. ${ }^{\text {a }}$ ed. corregida y aumentada), 100-101. 
Gracias a las mañas de los portugueses en pasar el dinero de los moriscos, éstos pueden embarcar en Francia pólvora y armas que llevar a Túnez y Constantinopla, donde son bien recibidos. Muchos moriscos, sin embargo, han vuelto a su tierra por «Fuente Rauía» para recoger el dinero que dejaron allí escondido, gracias a unas cédulas con la firma del Conde de Salazar falsificada por el morisco de Almagro Francisco el Gordo, a razón de trescientos reales la cédula.

La mecánica de la evasión del dinero y las joyas consiste, en resumen, en que los portugueses los sacan de los lugares de origen de los moriscos y los llevan hasta Irún, en donde quedan a recaudo en una casa apartada que posee Martín Sabato de Olazábal. Éste posteriormente los saca de España con ayuda de su familia y los entrega a los ya citados Antonio Méndez Cardoso y Francisco Núñez, quienes son los encargados de pasar el dinero a los moriscos. Señala Suárez que los moriscos que se encargan de las «correspondencias» en Francia son Francisco de Valencia y el abulense Fabián Maroto, ambos en San Juan de Luz, y Jerónimo Enríquez en Bayona, denominados «procuradores de los desta naçión». Enríquez envía las cartas que le llegan a dos judíos en Venecia, Abraham Zacuto y Abraham Muguión, quienes son finalmente los que las hacen llegar a Túnez y a Turquía.

Advierte asimismo el espía Suárez de que en esas mismas fechas de 1612 los moriscos de dentro y de fuera de España siguen teniendo contacto más o menos fluido, como muestra con el caso de Francisco Toledano, morisco de Madrid. Éste, posiblemente en Francia, ha recibido una carta en la que se le pide que avise a dónde va y que espere a sus corresponsales, que pronto partirán a Marsella y después a Roma, que - avisa Lorenzo Suárez- es el nombre clave con el que denominan a Constantinopla. El último aviso habla de la llegada a Constantinopla de ricos moriscos (Francisco Toledano, Lasarte y los Bejaranos) ${ }^{5} \mathrm{y}$ de que han puesto al corriente al Gran Turco sobre los «agravios de España», quien les ha concedido todo lo que pidieron, como hacen saber a Jerónimo Enríquez, ahora citado en Marsella.

A estos testimonios sigue otro informe acerca de una carta escrita por Gabriel de Carmona, «vezino de las Çinco Villas de Campo de

5 Véase la carta escrita desde París a Constantinopla por el morisco Ahmad al-Haŷarī, haciéndose eco de esos notables moriscos llegados a Turquía, en Oliver Asín, J., "Aḥmad al-Ḥaŷarī Bejarano. Apuntes biográficos de un morisco notable residente en Marruecos", en idem, Conferencias y apuntes inéditos, Madrid, 1996, 151-164.

Al-Qanțara (AQ) XXIX 2, julio-diciembre 2008, pp. 307-332 ISSN 0211-3589 
Calatraua», el 13 de julio de 1612. Éste, morisco expulsado pese a sus reivindicaciones de la antigua fidelidad de su familia al rey de España, da cuenta de sus actividades de espionaje entre los moriscos en Francia a favor del rey. Conocedor del procurador morisco Francisco de Valencia, cita asimismo a Jerónimo Enríquez, «natural de la Manchuela de Xaén», y cuenta cómo éste a través de San Juan de Luz e Irún pasa la correspondencia de los moriscos hacia España y asimismo cómo los judíos portugueses, los únicos de los que se fían los moriscos, son los que pasan el dinero de España a Francia.

La documentación ofrecida por estos espías del rey en Francia no deja mucho lugar a dudas acerca de que los moriscos contaban ya muy a principios de 1612 con una más o menos sólida infraestructura y una red de contactos que les permitía poder salvar las prohibiciones de los bandos de expulsión acerca de sacar sus riquezas. Es patente, de la misma forma, que los judeoconversos portugueses, establecidos desde hacía unas décadas en España ${ }^{6}$, jugaban un papel de primer orden en todo este plan de fuga de capitales. La colaboración entre ambos grupos era evidente y parecía desde luego bastante bien coordinada. Las llamadas de atención de los espías reales no hacen sino confirmar los continuos éxitos de estas redes volcadas hacia el exterior.

Unos magníficos trabajos de Jesús Carrasco Vázquez a partir de los archivos inquisitoriales y asimismo del Archivo de Simancas permiten profundizar tanto en las vicisitudes de este grave asunto como en las personas de algunos de sus protagonistas ${ }^{7}$. Cuando se decretó la expulsión de los moriscos, se determinó para ellos la prohibición absoluta de sacar con ellos oro, joyas y dinero que pudieran aprovechar a los enemigos de España, si bien en 1610 se les permitió sacar la mitad de sus bienes ${ }^{8}$. Para impedir el más que previsible trasiego ile-

${ }^{6}$ Domínguez Ortiz, A., La clase social de los conversos en Castilla en la Edad Moderna, Madrid, 1955, 84-87.

7 Carrasco Vázquez, J., "Moriscos y marranos. Colaboración interesada de dos colectivos marginados en tiempos del Quijote", III Congreso sobre la Orden Militar de San Juan. Historia de la Orden de San Juan en tiempo del Quijote (Alcázar de San Juan, febrero de 2005), en prensa; idem, "Un espía morisco al servicio de Felipe III", X Simposio Internacional de Mudejarismo (Teruel, septiembre de 2005), en prensa. Quiero señalar mi agradecimiento a Jesús Carrasco por proporcionarme copias de estos últimos trabajos suyos todavía inéditos.

8 Domínguez Ortiz, A. y Vincent, B., Historia de los moriscos. Vida y tragedia de una minoría, Madrid, 1985, 177-178, 186-187; Epalza, M. de, Los moriscos antes y después de la expulsión, Madrid, 1992, 126-129.

Al-Qanțara (AQ) XXIX 2, julio-diciembre 2008, pp. 307-332 ISSN 0211-3589 
gal, se estableció un control en Burgos bajo el mando del Conde de Salazar.

Fueron sin embargo los judeoconversos quienes aprovecharon estas circunstancias para hacer un negocio redondo ${ }^{9}$ : convencieron a los moriscos de que lo que llevasen les sería irremisiblemente decomisado por las autoridades y que sólo si lo ponían en sus manos podrían salvar su capital y ponerlo a buen recaudo en Francia. El aval que les recomendaba ante los moriscos lo obtuvieron del ya citado Francisco de Valencia, rico comerciante con muy buenas relaciones en Marruecos y aliado de Mawlāy Zaydān en su lucha por el trono. Con un precio que oscilaba entre el 20 y el 30 por 100 del valor de lo evadido, los conversos lograron sacar sin duda importantes cantidades de dinero y joyas amparados en las extensas redes familiares y comerciales que habían logrado tejer principalmente entre Castilla y el sur de Francia ${ }^{10}$.

A este negocio de pingües beneficios hay que añadir, además, el del contrabando de moneda de vellón falsificada, que introducían en Castilla a cambio de reales de plata, seguramente aprovechando también los desplazamientos moriscos. De todo ello se hará lenguas el espía morisco Gabriel Carmona, de quien Carrasco Vázquez nos descubre su nombre completo, Gabriel Carmona Vanegas, morisco antiguo natural de Almagro, donde nació en $1586{ }^{11}$. Sus servicios al rey, sin embargo, denunciando a los judeoconversos portugueses en Madrid en 1615 , le serán pagados con destierro, cárcel y tormento a manos de la Inquisición merced a una trama urdida por aquéllos y sus poderosos contactos dentro de la Corte.

La realidad de una cooperación efectiva entre judeoconversos y moriscos en el tránsito de éstos de suelo español al francés parece innegable y se prolongará durante más tiempo. En la Francia de María de Médicis y de Luis XIII seguirán siendo muy abundantes los con-

9 Sigo en lo principal a Carrasco Vázquez, "Moriscos y marranos".

10 Caro Baroja, J., Los judios en la España Moderna y Contemporánea, Madrid, 1986, I, 270-275; Israel, J.I., "El comercio de los judíos sefardíes de Ámsterdam con los conversos de Madrid a través del suroeste francés", en J. Contreras et al., Familia, religión y negocio. El sefardismo en las relaciones entre el mundo ibérico y los Países Bajos en la Edad Moderna, Madrid, 2003, 373-390.

${ }^{11}$ Carrasco Vázquez, J., "Contrabando, moneda y espionaje (el negocio del vellón: 1606-1620)", Hispania, LVII, 3, 197 (1997), 1081-1105, para todo el asunto en global que denunció Gabriel Carmona. Para la figura y acción concretas de este morisco, véase su trabajo "Un espía morisco al servicio de Felipe III".

Al-Qanțara (AQ) XXIX 2, julio-diciembre 2008, pp. 307-332 ISSN 0211-3589 
tactos entre conversos portugueses y moriscos, y algunos de ellos además dentro de los más altos círculos sociales. Así parece probarlo el caso de Alfonso o Alonso de López, aragonés y soi-disant descendiente de los Abencerrajes, joyero y tratante de objetos de lujo en la alta sociedad parisina y que acabará su azarosa vida en Francia ejerciendo de agente del Cardenal Richelieu. Éste, a quien documentos contemporáneos asignan una discutida identidad judía, se verá envuelto en 1617, junto con un grupo de conversos portugueses, en un muy confuso caso de hechicería de la favorita de la reina, mezclado con asesinatos investigados por las autoridades ${ }^{12}$. De la misma forma, como muestra la estupenda biografía de Samuel Pallache, entre África y Europa serán numerosas las ocasiones de colaboración entre ambas comunidades: diplomacia, espionaje, piratería o política constituirán espacios de encuentro, cooperación y conflicto entre moriscos y judíos ${ }^{13}$. Igualmente el comercio y rescate de esclavos será también una actividad en la que conversos y moriscos cruzarán frecuentemente sus destinos ${ }^{14}$. Aunque en suelo hispano no conocemos muy abundantes casos de cercanía y colaboración de estos dos grupos que, en ocasiones, tenían objetivos y aspiraciones sociales opuestos, la oportunidad de un buen provecho hizo que los portugueses se acercaran a las ciudades que antes de la expulsión albergaban un buen número de moriscos para ofrecer sus servicios ${ }^{15}$. El hacer pasar sus haciendas

${ }^{12}$ La azarosa vida de Alonso de López, que se mueve entre su ascendencia entre la comunidad morisca, sus contactos con los conversos de judío instalados en Francia y su gran familiaridad con las autoridades francesas, aguarda todavía un estudio en profundidad que ponga orden en las gruesas y flagrantes contradicciones que se revelan en la bibliografía a él dedicada. Véase: Baraude, H., López agent financier et confident de Richelieu, Paris, 1933; Pelorson, J.M., "Le docteur Carlos García et la colonie hispano-portugaise de Paris (1613-1619)", Bulletin Hispanique, 71 (1969), 518-576; Caro Baroja, J., "El último Abencerraje", en idem, Vidas poco paralelas (con perdón de Plutarco), Madrid, 1981, 51-68; Hildesheimer, F., "Une créature de Richelieu: Alphonse Lopez, le 'Seigneur Hebreo", en Les juifs au regard de l'histoire. Mélanges B. Blumenkranz, París, 1985, 293-299; Sauzet, R., "Alonso Lopez, procureur des Morisques aragonais et agent de Richelieu (1582-1649)", en A. Temimi (ed.), Actes du II ${ }^{e}$ Congrès International sur: Chrétiens et Musulmans à l'époque de la Renaissance, Zaghouan, 1997, 213-219; Santoni, P., "Le passage des morisques en Provence (1610-1613)", Provence Historique, 185 (1996), 333-383, 367 y ss.; García-Arenal y Wiegers, Entre el Islam y Occidente, 158-160.

13 García-Arenal y Wiegers, Entre el Islam y Occidente, 77-80, 102-104, 146, 153.

14 Epalza, M. de, "Moriscos y andalusíes en Túnez durante el siglo XVII", Al-Andalus, XXXIV, 2 (1969), 247-328.

15 Véanse los casos expuestos en López Belinchón, B., Honra, libertad y hacienda (hombres de negocios y judios sefardies), Alcalá de Henares, 2001.

Al-Qanțara (AQ) XXIX 2, julio-diciembre 2008, pp. 307-332 ISSN 0211-3589 
entre España, Francia y Túnez fue sin duda uno de los más solicitados y mejor pagados.

\section{Entre Francia y Túnez}

La emigración morisca a Túnez tras la expulsión general de 1609 ha sido la más y mejor estudiada, especialmente desde la segunda mitad del siglo XX. La política otomana de apoyo y acogimiento en su Regencia norteafricana, los lugares de instalación de los moriscos, su inserción social y laboral, su vida intelectual y su legado en la toponimia, urbanismo, agricultura, lengua, etc., son aspectos que han merecido numerosos y, en muchos casos, excelentes estudios ${ }^{16}$. Del mismo modo, el papel político del dey 'Uțmān y la indispensable labor socio-religiosa del venerable santón Abū l-Gayt al-Qaššǎš en el acogimiento de los miles de moriscos que llegan a Túnez desde Francia, han sido puestos justamente de relieve desde antiguo y, más recientemente, en un excelente trabajo de Míkel de Epalza ${ }^{17}$ a partir de la aparición de la biografía de al-Qaššāš redactada en 1634 por uno de sus discípulos.

Sin embargo, el trasvase de los moriscos a la Regencia tunecina y sus primeros momentos de organización comunitaria, han recibido una menor atención crítica. Como si los moriscos en Túnez comenzasen su vida ex novo, no han sido demasiado tenidos en cuenta los antecedentes que los ligan en primera instancia a su precaria organización social en Francia y, más allá, a sus lazos familiares y grupales en España. Del mismo modo, seguramente no han sido suficientemente valorados algunos factores que pueden revelarse como importantes a la hora de comprender de forma cabal la instalación morisca en Túnez: en especial, la abundante y muy temprana afluencia de granadinos - de ricos granadinos - a la Regencia otomana y, asimismo, la especial personalidad de algunas de las más destacables autoridades entre los moriscos en Francia y en Túnez.

16 Ver, como recopilaciones de trabajos, Epalza, M. de y Petit, R. (eds.), Études sur les moriscos andalous en Tunisie, Madrid-Tunis, 1973; Zbiss, S. M., Gafsi, A., Boughanmi, M. y Epalza, M. de (eds.), Etudes sur les Morisques Andalous, Túnez, 1983.

17 Epalza, M. de, "Sidi Bulgayz, protector de los moriscos exiliados en Túnez (s. XVII). Nuevos documentos traducidos y estudiados", Sharq Al-Andalus, 16-17 (1999-2002), 141-172.

Al-Qanțara (AQ) XXIX 2, julio-diciembre 2008, pp. 307-332 ISSN 0211-3589 
Hace algunos años, cuando estudiaba la obra en castellano de uno de estos moriscos instalados en Túnez, el toledano Juan Pérez o Ibrahim Taybilī ${ }^{18}$, comprobaba cómo algunos de estos moriscos desarrollaron en sus nuevos destinos una capacidad de escritura que seguramente no se les había pasado por la cabeza cuando vivían en España. Dado su nivel cultural, posiblemente, pronto aprendieron los suficientes conocimientos islámicos como para poder enseñar a sus compatriotas en castellano los errores de los cristianos y las virtudes de ese islam por el que habían sido expulsados de España. Esta atractiva literatura islámica en castellano, que en ocasiones se trufaba de recuerdos y vivencias de España, era de alguna manera otra prueba de los modos de inserción de estos moriscos, muchos de ellos hispanohablantes, en Túnez, como una forma de romper definitivamente con lo que habían dejado atrás ${ }^{19}$.

Sin embargo, al estudiar posteriormente el Evangelio de San Bernabé, enfocado como el último y más sofisticado fruto de la fantástica conspiración granadina de los libros plúmbeos del Sacromonte ${ }^{20}$ y que manejaban los moriscos en Túnez, pude comprobar que lo que podía ser visto como el descuaje de una comunidad con su vida anterior y el comienzo de una vida completamente ajena, no lo era tanto. Y las matizaciones a esa idea podían además tener consecuencias en el modo de contemplar la temprana instalación de los moriscos en Túnez.

Ibrahim Taybilī, en efecto, cita en un momento de su polémica anticristiana a los libros plúmbeos del Sacromonte como prueba a propósito de la prevaricación de los apóstoles falsificando el verdadero mensaje de Dios. Porque una copia de los libros plúmbeos existía en efecto en Túnez, según el testimonio del morisco Aḥmad al-Haŷarī (c. 1637), que los conocía perfectamente por haber trabajado en su traducción en Granada por mandato del Arzobispo. Esta copia, que

18 Bernabé Pons, L.F., El cántico islámico del morisco hispanotunecino Taybili, Zaragoza, 1988; idem, "L'écrivain morisque hispano-tunisien Ibrahim Taybili (Introduction à une Littérature Morisque en Tunisie)", Mélanges d'Archéologie, d'Épigraphie et d'Histoire offerts à Slimane Mustapha Zbiss, Tunis, 2001, 249-272.

19 Ver, por ejemplo, Penella, J., "Littérature morisque en espagnol à Tunis", en Epalza y Petit, Etudes sur les moriscos, 187-198; Harvey, L.P., "Textes de littérature religieuse des moriscos tunisiens", en Epalza y Petit, Études sur les moriscos, 199-204.

20 Bernabé Pons, L.F., El evangelio de San Bernabé. Un evangelio islámico español, Alicante, 1995; idem, El texto morisco del Evangelio de San Bernabé, Alicante-Granada, 1999.

Al-Qanțara (AQ) XXIX 2, julio-diciembre 2008, pp. 307-332 ISSN 0211-3589 
había sido efectuada por uno de los traductores oficiales en Granada, al-Ukayhal, fue llevada a Túnez por el ya difunto alfaquí Yūsuf Qalbu al-Andalusī en una fecha que no conocemos ${ }^{21}$. Este Yūsuf Qalbu podría quizá ponerse en relación con el Juan Calvo «escribano en el escritorio de la hacienda y población del reino de Granada», que en marzo de 1616 escribe cartas a tres moriscos granadinos, Felipe de Padilla, Rodrigo Zapata y Luis Zapata ${ }^{22}$. Esta correspondencia será interceptada por el duque de Osuna en Palermo y, de hecho, en octubre de 1616 se ordena en Granada la vigilancia y arresto del dicho Juan Calvo, ordenando asimismo la confiscación de todos los documentos que se le hallen, en especial su correspondencia con los tres moriscos mencionados.

Las tres cartas de Calvo que el duque de Osuna envía desde Palermo al rey contienen noticias realmente interesantes: a Rodrigo Zapata le señala que «tiene grandes prendas del licenciado, que Dios perdone, que si no es él no son para que otro guste dellas; que si el bien no es comunicado, no es estimado». Del mismo modo, le informa de que «el amigo Miguel de Luna murió y se quedaron los razonamientos suspensos hasta que Dios quiera que el tiempo los menee». Estas referencias a un licenciado y la segura noticia de la muerte de Luna nos pueden llevar a algún tipo de conjeturas: ¿qué prendas del licenciado eran las que esperaban exclusivamente a Rodrigo Zapata?, ¿qué razonamientos eran esos que quedan suspensos por la muerte de Luna a la espera de que el tiempo los active? Aunque es cierto que por ahora no pueden establecerse sino conjeturas, podría ser que tras estas preguntas se ocultara la clave para resolver el enigma del libro mudo del Sacromonte, ese libro que prometía un evangelio verdadero y que, en mi opinión, en forma del evangelio islámico de San Bernabé, va a aparecer nombrado por primera vez precisamente entre los moriscos exiliados en Túnez ${ }^{23}$.

21 Ver la edición de Van Koningsveld, P.S., al-Samarrai, Q., y Wiegers, G., Kitāb Nāṣir al-dìn, Madrid, 1997, 245 (inglés), 190 (árabe).

22 AGS, Leg. 1170, publicado en CODOIN, t. XLV, 1864, doc. CCCLXXIX, 390-393. Ver también Van Koningsveld, al-Samarrai y Wiegers, Kitāb Nāsirir al-dīn, 53.

${ }^{23}$ Epalza, M. de, "Le milieu hispano-moresque de l'Evangile islamisant de Barnabé (XVI'-XVII ${ }^{\mathrm{e}}$ siècle)", Islamochristiana, VIII (1982), 159-176; Bernabé Pons, L.F., "Los mecanismos de una resistencia: los libros plúmbeos del Sacromonte y el Evangelio de Bernabé", Al-Qanțara, XXIII, 2 (2002), 477-498; también en Barrios Aguilera, M. y García-Arenal, M. (eds.), Los plomos del Sacromonte. Invención y tesoro, Valencia, 2006, 385-342. 
Finaliza Juan Calvo su misiva a Rodrigo Zapata diciéndole que va a buscar para enviarle el «privilegio de los Habenceides» y le señala, lo mismo que a Felipe de Padilla, que la correspondencia que puedan enviarle «sea por Palermo, por mano de Luis Zapata, que está con el duque de Osuna». Al mismo Luis Zapata escribe también el granadino Calvo diciéndole que Felipe de Padilla, sobrino de su mujer, y Rodrigo Zapata se encuentran en Aviñón, pidiéndole que «les encamine sus cartas, y que si hubiere ocasión de que respondan por aquella vía, lo haga y le encamine las cartas a Pedro de Aguilar, agente del duque de Osuna, que está en Granada». El documento concluye con la propia opinión del duque, que no deja lugar a dudas acerca de su opinión: «este Luis Zapata es uno de los expelidos y tiene su casa y parientes en Túnez, y [...] los que de acá le escriben son tan moros como los que allá están».

En efecto, el granadino Luis Zapata, el «alguacil mayor» de los moriscos expelidos en Túnez en una primera etapa y antecesor del gran Mustafá de Cárdenas como cabeza visible de la comunidad morisca, se encontraba desde 1613 en Palermo retenido por el duque de Osuna y por la Inquisición. A través de tres documentos del Archivo General de Simancas ${ }^{24}$ — dos copias de cartas del duque de Osuna y una copia de minuta de consulta del Consejo de Estado-, podemos seguir la peripecia de Zapata: en un viaje de Túnez a Marsella en febrero o marzo de 1613, su nave, un bajel francés, se ve obligada por el temporal a atracar en Trapani. Allí, los once moriscos que van en la nave, aunque portan trajes cristianos, son reconocidos, retenidos y conducidos a Palermo. El virrey da enseguida cuenta a Su Majestad, señalando como los dos moriscos más principales a Luis Zapata y a Juan Pérez, morisco de Pastrana. Interrogados, señalan que se dirigían a Marsella para establecerse allí, aunque el duque señala: «Háseme hecho dificultoso creellos, por dejar sus casas en Túnez, y ser el uno dellos Luis Zapata, de quien se han servido por alguacil mayor, y otro un Juan Pérez de Pastrana, hombre que tenía alguna hacienda, que son los dos que dejan sus casas en Berbería», consultando acto seguido al rey qué es lo que se debe hacer con ellos.

La minuta del Consejo de Estado (30 de abril de 1613) nos da cuenta de las deliberaciones. Las posturas están enfrentadas: el mar-

24 AGS, Leg. 1166; CODOIN, t. XLIV, 1864, docs. CLV, CLXI y CXCIII.

Al-Qanțara (AQ) XXIX 2, julio-diciembre 2008, pp. 307-332 ISSN 0211-3589 
qués de Castel Rodrigo y el duque del Infantado piensan que se trata de una transgresión de los bandos de expulsión y que, por tanto, han de ser tomados como esclavos. El comendador mayor de León, el marqués de Velada, el marqués de Villafranca, don Agustín Mexía, el marqués de la Laguna y el cardenal de Toledo no tienen, con matices, a esos moriscos por esclavos, pero piensan que estaría bien escarmentarlos públicamente y anunciar que a partir de ese momento con cualquier morisco se aplicarán las medidas previstas en los bandos. Esto último será lo que se decida hacer.

En octubre de 1613 el duque de Osuna vuelve a referirse a este asunto a instancias del rey, quien desde San Lorenzo se muestra preocupado porque ha llegado a sus oídos que hay en Palermo unos moriscos que andan libremente «en hábito de moros» y que incluso uno de ellos está refugiado en casa del duque, que se niega a entregarlo a la Inquisición. El duque tranquiliza a Su Majestad: eran los moriscos a los que se había referido en su correspondencia anterior, y para mayor tranquilidad señala que iban en hábito de cristianos. El morisco refugiado en su casa es Luis Zapata, que efectivamente había sido reclamado por la Inquisición de Palermo. La demora en entregarlo la había producido la espera de la contestación del rey a su demanda anterior, pero de cualquier forma ya lo ha entregado al tribunal «donde está preso — señala el duque - pienso que con poco fundamento». Los otros moriscos, dejados libres, han preferido volver a Berbería y no a Francia ${ }^{25}$. El virrey no se engaña: «la causa verdadera es que ellos son moros y van a cobrar en Marsella alguna hacienda, y volverse a Túnez donde dejan sus hijos y mujeres».

Hasta ahora el caso no presenta una gran novedad, excepción hecha del rango reconocido al prisionero morisco. Sin embargo, el documento prosigue ofreciendo algunas notas de mucho interés: señala el duque que cuando Zapata salga de prisión, avisará al rey de algunos negocios que con él va tratando y añade:

Deseo saber de V. M. si alguno de los [moriscos] de los que viven en Túnez, con quien yo tengo correspondencia secreta para los avisos de Berbería y Levante, se ofrece a venir a este reino en achaque de rescatar esclavos, en qué traje ha de andar siendo moro y echado de España por tal, pues en las galeras de V. M. el

${ }^{25}$ Sobre las importantes actividades mercantiles posteriores de este Juan Pérez ver Epalza, "Moriscos", 275-277.

Al-Qanțara (AQ) XXIX 2, julio-diciembre 2008, pp. 307-332 ISSN 0211-3589 
morisco que se toma en corso, que dice que es cristiano, se le deja vivir como tal, y el que dice que es moro, trae copete.

El decreto del rey, copiado al fin del documento, no deja lugar a dudas:

Que los que sirvieren de espías anden con el traje que les pareciere para disfrazarse más, y los otros que dice, en el que quisiere, según la costumbre que ha habido.

Aparte de la reveladora noticia de que el duque de Osuna cuenta con espías entre la comunidad morisca instalada en Túnez, que le van informando de lo relativo a los asuntos turcos y norteafricanos, cabe preguntarse de qué negocios estaba tratando con una de las máximas autoridades de los moriscos expulsados. ¿Se estaba ganando a otro espía, esta vez de un calibre superior? ¿O también estaba ganándose a un rescatador de esclavos de primer orden, capaz de poder establecer negociaciones vedadas a otros? Porque lo cierto es que Zapata, como ya señaló Epalza a partir de documentación del Consulado francés de Túnez, debió de salir pronto de las cárceles de la Inquisición. El Santo Oficio lo había aprisionado a propósito de la muerte en Túnez de un sacerdote de Pisa, quemado vivo en agosto de 1612 por orden de Yūsuf Dey, a causa de insultos al Profeta en una polémica seguramente con moriscos. Su esposa alegará en su defensa que cuando ocurrieron los hechos ya no era ninguna autoridad entre los moriscos y que no había intervenido en dicha muerte. Los argumentos, y seguramente el interés del virrey, debieron de pesar bastante para su liberación, porque entre 1614 y 1615 vemos a Luis Zapata actuando como procurador y prestamista en el rescate de esclavos cristianos, como el caballero sanjuanista Juan de Silva, un monje griego de la orden de San Basilio, tres sicilianos esclavos de renegados y del propio Yūsuf Dey, y otros casos similares ${ }^{26}$. Posiblemente su formación bilingüe, el prestigio que tenía tanto entre sus compatriotas moriscos y entre las autoridades tunecinas, y su capacidad de organización mostrada en su estancia con los moriscos en Francia, lo hacían un personaje ideal tanto para ser un agente doble como para realizar negociaciones que comportaran algún tipo de dificultad. Túnez, como otros lugares de interés político, se abría también a la red de espionaje que España ha-

26 Epalza, "Moriscos", 284-288.

Al-Qanțara (AQ) XXIX 2, julio-diciembre 2008, pp. 307-332 ISSN 0211-3589 
bía ido tejiendo desde hacía años y que poco a poco ha ido siendo desvelada por la historiografía ${ }^{27}$. Por su parte, Luis Zapata ganaba, aparte de seguridad y libertad de acción (ya hemos visto cómo en 1616 Juan Calvo le hace transmisor de su correspondencia merced a su relación con el duque de Osuna), una forma lucrativa de ganarse la vida, y todo ello sin, al parecer, perder la confianza de los tunecinos o de los moriscos pese a dejar de ser su autoridad.

La figura de Luis Zapata ha estado íntimamente ligada a la de Mustafá de Cárdenas en tanto que ambos parecen ser las dos primeras autoridades de la comunidad morisca asentada en Túnez a partir de 1610. Figura preeminente de su comunidad el primero. Auténtico jeque de los moriscos y figura social, económica y política de primer orden en Túnez durante treinta años el segundo. ¿Es un azar, o tienen elementos comunes que de alguna manera los relacionen? Seguramente, ambos mercaderes granadinos de calidad y medios ${ }^{28}$, los dos parecen poseer un sentido de la solidaridad grupal y una capacidad humana y material para la organización que los ponen en primera línea de los moriscos exiliados en Francia y que después les hacen ser los delegados jefes de su comunidad en Túnez. Pero, ¿existe alguna razón concreta — si es que tuviera que haberla - por la cual los dos primeros jefes conocidos de los moriscos en Túnez son dos granadinos venidos de Francia?

${ }^{27}$ Sobre la conformación y actuación de los agentes secretos al servicio de España en el siglo XVI, en el norte de África y en Turquía véase Sola, E. y Peña, J.F., Cervantes y la Berbería, Madrid, 1995; y Floristán Imizcoz, J.M., Fuentes para la politica oriental de los Austrias, León, 1988, II, 579-737. Abundantes datos para conocer la amplia red de espionaje tejida por Felipe II en Téllez Alarcia, D., "El papel del norte de África en la política exterior de Felipe II. La herencia y el legado", Espacio, Tiempo y Forma, Serie IV, H. Moderna, 13, 2000, 385-420. Accesible on-line en: http://e-spacio.uned.es/fez/view.php?pid=bibliuned: ETFSerie4-061B97AE-1304-0D32-044E-39F69F6A7C75 (10/08/2008)

28 J.D. Latham ("Muçtafa de Cardenas et l'apport des 'morisques' à la société tunisienne du XVIIe siècle", en Zbiss, Gafsi, Boughanmi y Epalza, Études sur les Morisques andalous, 157-177) se inclina por un origen de Baeza para Cárdenas, a partir del testimonio de Marcos de Guadalajara. No ha de olvidarse que los Cárdenas eran una de las más importantes familias de Granada dedicadas a la industria y el comercio de la seda (Javier Castillo Fernández, "Estructuras sociales", en Barrios Aguilera, M. (ed.), Historia del Reino de Granada, II, Granada, 2000, 202), hasta el punto de que su fortuna se contaba entre las más grandes del mundo granadino en la segunda mitad del siglo XVI (Vincent, B., "Les élites morisques grenadines", en P. Civil (ed.), Siglos Dorados. Homenaje a Augustin Redondo, Madrid, 2004, II, 1467-1479).

Al-Qanțara (AQ) XXIX 2, julio-diciembre 2008, pp. 307-332 ISSN 0211-3589 


\section{De nuevo en Francia}

Luis Zapata, como Mustafá de Cárdenas, las dos primeras cabezas visibles de los moriscos instalados en Túnez, no eran unos hombres cualesquiera a los que les tocó en suerte su destino como autoridades entre sus compatriotas. Los lazos que les unían ya se habían establecido en Francia en los años inmediatamente posteriores a la expulsión cuando alrededor de los puertos sureños franceses llegó una avalancha de moriscos granadinos, aragoneses y castellanos. Gracias a obras como las de L. Cardaillac ${ }^{29}$, J. Penella ${ }^{30}$, J. D. Latham ${ }^{31}$ y, más recientemente, el minucioso artículo de Pierre Santoni ${ }^{32}$, estamos informados de bastantes de los principales acontecimientos del paso de los moriscos por Francia como vía de su tránsito hacia países islámicos. Acogidos en un principio de forma favorable gracias a la política de Enrique IV, los primeros granadinos que llegaron a Francia en 1610 pudieron instalarse sin mayores inconvenientes a la espera de su embarque hacia, normalmente, Túnez. Sin embargo, la posterior llegada masiva de varios millares de moriscos aragoneses, unida al asesinato del rey Enrique, hizo cambiar las tornas para los moriscos, que comenzaron a ser vistos como una presencia incómoda y peligrosa en tierras francesas, y fueron impelidos a partir cuanto antes, pagando generalmente los moriscos más ricos los costes del pasaje de los más pobres.

En esta estancia de los moriscos en Francia, las autoridades se vieron pronto en la necesidad de designar a algunos representantes de la comunidad morisca que les sirvieran de interlocutores y que actuaran asimismo como autoridad entre los suyos. La documentación recogida por Santoni habla al principio genéricamente de unos «jefes» de los aragoneses que se encontraban en un lamentable estado en las enfermerías de Marsella, pero más tarde va a comenzar a ofrecer nombres de moriscos concretos que van a desempeñar este papel, recogiendo las contribuciones de sus compatriotas para fletar barcos que lleven a Túnez a los pobres, buscando ellos mismos los barcos y orga-

29 Ver sus trabajos en Epalza y Petit, Études sur les moriscos, 89-113.

30 Ibidem, 64-73.

31 "Towards a study of Andalusian Immigration and its place in Tunisian History", Les Cahiers de Tunisie, V (1957), 203-252 (trad. fr. en Epalza y Petit, Études sur les moriscos, 21-63).

32 "Le passage des morisques", 333-383.

Al-Qanțara (AQ) XXIX 2, julio-diciembre 2008, pp. 307-332 ISSN 0211-3589 
nizando los viajes, protestando ante las autoridades por algún trato injusto, reclamando los bienes robados por algún capitán o marinero desaprensivo, etc. Así, van a aparecer los nombres del ya conocido comerciante instalado en Marsella Jerónimo Enríquez como «procurador general de los moriscos»; Gabriel Esquierlo y Luis Zapata, nombrados comisarios de los moriscos en 1610 por el comisario real Honoré Aymar; Diego de Cárdenas (más tarde Mustafá) como corresponsal o encargado de asuntos de los moriscos; el citado Alonso de López; Tristán Océn y Pedro Vivera, nombrados en Martigues comisario y controlador de los moriscos aragoneses; Juan Pérez, Lorenzo Diego y Alonso Hernández como comisarios de los moriscos castellanos en Montpellier.

No sabemos en realidad cuáles eran los motivos por los que estas personas recibían el encargo de la representación formal de los distintos grupos moriscos establecidos en Francia. En el caso de hombres como Jerónimo Enríquez o Alonso de López, ya establecidos en Francia anteriormente y con bastantes contactos entre la sociedad y las autoridades francesas, podemos suponer que su propia circunstancia facilitaría su condición de puente entre unos y otros. En otros casos, como los de Luis Zapata, Diego de Cárdenas ${ }^{33}$, Miguel Enríquez o Alonso Hernández, su condición de comerciantes y hombres económicamente pudientes, los haría además propicios para dirigir los embarques de los moriscos, poder conseguir el dinero necesario para pagar los viajes o pleitear por los bienes de aquéllos que hubieran podido ser expoliados, como será el caso de Alonso Hernández o un tal Luis Margnon (¿Marañón?) ${ }^{34}$. Se trataría en cualquier caso de hombres que, por su condición social, poderío económico o relaciones políticas asumen, al parecer de grado, un papel representativo de la minoría morisca que en ningún momento parece ser discutido ni por algún miembro de ésta ni por otros delegados. El hecho de que Zapata y Cárdenas perpetúen sus funciones entre los moriscos en Tú-

33 «Il reste cependant des Morisques jouissant d'une certaine envergure économique et tenant une place particulière en marge de la masse de leurs compatriotes. Il est notamment deux qui semblent installés à demeure à Marseille, et dont on peut se demender s'ils ne s'y trouvaient pas déjà avant 1610. C'est d'abord Diego de Cardena, que l'on voit impliqué financièrement, au début 1610, dans le transport des Grenadins d'Andujar», "Le passage des morisques", 366.

34 Ibidem, 365.

Al-Qanțara (AQ) XXIX 2, julio-diciembre 2008, pp. 307-332 ISSN 0211-3589 
nez, el segundo durante décadas, testimonia tanto lo sólido de sus posiciones ya en Francia, como lo indiscutido de su autoridad.

Podría añadirse a los motivos anteriormente expuestos otro matiz derivado del origen de estos hombres. En efecto, una de las circunstancias que más llama la atención de todo este período de reorganización de los moriscos en Francia, a la vista de sus autoridades, es la innegable abundancia de granadinos pertenecientes a algunas de las más conocidas familias del antiguo reino. Ya se ha señalado el poderío económico de los Cárdenas al hablar del mercader Diego/Mustafá de Cárdenas, la gran autoridad de los moriscos en Túnez en la primera mitad del siglo, o la evidente relación de Luis y Rodrigo Zapata con ciertas esferas de Granada. También se encuentra en esta nómina un Alonso Hernández de Porras Adoladín, que pleitea por unos bienes expoliados a los moriscos, y a quien se relaciona sin esfuerzo con la familia Abduladín, una de las más integradas en la sociedad cristiana del Reino de Granada y antiguos señores de moriscos ${ }^{35}$. Podría ser, seguramente, el caso también de Jerónimo Enríquez: éste parece disponer tanto de contactos con la Sublime Puerta, como de los recursos y autoridad suficientes para aglutinar en torno a sí a un buen número de moriscos. Aunque se le atribuye de ordinario origen aragonés, el espía morisco Gabriel Carmona sitúa su nacimiento en Jaén: hay que tener en cuenta que la familia Enríquez es suficientemente conocida entre las más destacadas del Reino de Granada, por sí misma o en relación matrimonial con otras ${ }^{36}$. Además, un reciente descubrimiento de la profesora Carmen Ansón ${ }^{37}$ podría matizar todavía más la cuestión: según la documentación descubierta y analizada por ella, Cándida Compañero, la última representante de la rica y poderosa familia de comerciantes y terratenientes aragoneses, con redes comerciales en España y Francia ${ }^{38}$, contrajo matrimonio en segundas nupcias con un

35 Galán Sánchez, Á., Los mudéjares del Reino de Granada, Granada, 1991, 267-268.

36 Castillo Fernández, J., "'Hidalgos moriscos': Ficción histórica y realidad social. El ejemplo del linaje Enríquez Meclín de la tierra de Baza (siglos XV-XVIII)", en A. Temimi (ed.), Mélanges Louis Cardaillac, Zaghouan, 1995, I, 161-180; idem, "Luis Enríquez Xoaida, el primo hermano del rey católico (análisis de un caso de falsificación histórica e integración social)", Sharq Al-Andalus, 12 (1995), 235-254.

37 Ansón, C., "Diego de Rojas y Alonso Muley Enríquez y Merín de Fez: ilustres esposos de Cándida Compañero", Sharq Al-Andalus, 18 (2003-2007), 9-37.

38 Ver, para la familia Compañero, Fournel-Guerin, J., "Une famille morisque de Saragosse: les Compañero", Awrāq, 4 (1981), 179-183; Conte, A., "Nivel económico de los moriscos oscenses", VII Simposio Internacional de Mudejarismo. Actas, Teruel, 1999, 
Alonso Muley Enríquez y Merín de Fez, granadino residente hasta entonces en Sevilla ${ }^{39}$ y licenciado en leyes. Sabemos, a partir del trabajo pionero de María Jesús Rubiera sobre Francisco Núñez Muley y la bibliografía que ha generado ${ }^{40}$, de la ligazón de ese apellido con los linajes reales nazarí y meriní y del prestigio que entre los moriscos tenían quienes lo portaban. Conocemos que uno de los sobrinos de Cándida Compañero, Miguel Enríque Compañero, se mostraba activo en Túnez en $1612^{41}$. ¿Tendría también alguna relación el Jerónimo Enríquez, mercader de posición y prestigio en Francia, con este personaje granadino que se integra en la influyente familia de los Compañero, siguiendo una tendencia que se da abundantemente en Granada entre las grandes familias moriscas? ${ }^{42}$ ¿Aprovecharían éste y otros personajes similares unas redes fundamentalmente comerciales, establecidas desde antiguo entre los moriscos aragoneses y Francia? ${ }^{43}$.

Estos moriscos granadinos de buena familia que, de una manera $u$ otra, se ponen a la cabeza de sus comunidades en Francia no son, además, un caso aislado más allá de los Pirineos: es conocido el caso de

299-317; Ansón, C. y Gay, M.P., "Las familias moriscas expulsadas de Zaragoza: un análisis de su número y propiedades", en A. Temimi (ed.), Actes du VIIe Symposium International d'Etudes Morisques sur: Famille Morisque: Femmes et Enfants, Zaghouan, 1997, 72-90.

39 Más que posiblemente relacionado con esos Muley acusados de organizar un complot en Sevilla en 1580, entre los que sobresalen Hernando Muley y su yerno Álvaro Enríquez, principales encausados, pero también un Jerónimo y un Alonso Enríquez, tintoreros de 36 y 28 años respectivamente. Véase Domínguez Ortiz, A., "Desventuras de dos moriscos granadinos", en Homenaje al Profesor Jacinto Bosch Vilá, Granada, 1991, I, 90. Importantes aclaraciones sobre el alcance real del pretendido complot y las acusaciones en Cortés Peña, A.L., "Una consecuencia del exilio: los moriscos granadinos en Sevilla", en E. Belenguer Cebriá (ed.), Felipe II y el Mediterráneo, Madrid, 1999, II, 537-553; análisis de las figuras dentro de su contexto familiar a partir del trabajo de $\mathrm{Ru}-$ biera Mata en Vincent, B., "Histoire d'une déchéance: la famille des Fez Muley à Grenade au XVIème siècle", en N. Harwich (ed.), Hommage à Alain Milhou. Les Cahiers du CRIAR, 21, I, 2003, 69-79.

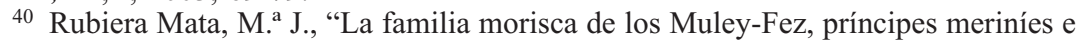
infantes de Granada", Sharq Al-Andalus, 13 (1996), 159-167; Vincent, "Les élites morisques grenadines"; García Luján, J.A. y Blázquez Ruiz, R.V., "Don Fernando Muley de Fez. Una información genealógica (1596) del linaje Granada Venegas", VIII Simposio Internacional de Mudejarismo. Actas, Teruel, 2002, II, 733-740; idem, "Don Pedro de Granada Venegas, I marqués de Campotéjar (1643), de Campo Rey y vizconde de Miravalles (1632)", VIII Simposio Internacional de Mudejarismo, II, 721-731.

41 Epalza, "Moriscos", 260, 277.

42 Vincent, "Les élites morisques grenadines", 1478.

${ }^{43}$ Conte, A., "La rama oscense de los Compañero (Apuntes biográficos)", Sharq Al-Andalus, 13 (1996), 129-144.

Al-Qanțara (AQ) XXIX 2, julio-diciembre 2008, pp. 307-332 ISSN 0211-3589 
un Alonso de Luna, quizá hijo de Miguel de Luna, encausado por la Inquisición de Murcia en 1618, que demuestra estar muy al tanto de los asuntos del Sacromonte ${ }^{44}$ y que atribuye su sospechoso conocimiento del árabe a su estancia con los moriscos en Francia. $\mathrm{O}$ un morisco granadino llamado El Chapiz ${ }^{45}$ y radicado en Toulouse en 1609 quien, junto a su suegro, daba alojamiento a los moriscos e incluso administraba el dinero que algunos moriscos le enviaban desde España y que pasarían a buscar más adelante ${ }^{46}$. Igualmente, el ya citado Rodrigo Zapata, posiblemente familiar de Luis, que se encuentra en Aviñón a la espera de recibir la notificación de un antiguo privilegio de sus ancestros musulmanes... El número de moriscos que, pertenecientes a conocidas familias de Granada, se sitúan y acomodan en Francia antes de la expulsión general de 1609 es sorprendentemente alto. Asimismo, su papel, una vez llegan los moriscos a las localidades y puertos franceses, resulta llamativamente homogéneo.

Desde luego, no sería difícil atribuir al oficio de la mercadería que varios ejercen una cierta movilidad y abundancia de contactos, pero resulta intrigante su presencia conjunta en zona y fechas tan críticas. Estamos aún lejos de poder entender completamente el sentido de esta activa presencia en Francia, que va a ser decisiva para el desvío de los moriscos hacia Túnez. Parece como si una red de contactos y ayuda que se hubiera estado tejiendo en años anteriores y que tuvo una actividad discreta con los moriscos pudientes que se anticiparon a la expulsión ${ }^{47}$, se pusiera, ahora que era necesario, en marcha, como ya había sucedido con anterioridad en España ${ }^{48}$. Esta red velaría por

44 Vincent, B., "Et quelques voix de plus: de Francisco Núñez Muley à Fatima Ratal", Sharq Al-Andalus, 12 (1995), 131-145; Wiegers, G., "Nueva luz sobre Alonso de Luna”, en Barrios Aguilera y García-Arenal, Los plomos del Sacromonte, 403-417.

45 Para la importancia de la familia Chapiz dentro de las élites moriscas, véase Álvarez de Morales, C., "Noticias sobre la Casa del Chapiz", Homenaje al profesor José María Fórneas Besteiro, Granada, 1995, II, 1139-1165; idem, "Lorenzo el Chapiz y el 'Negocio General' de 1559", Qurțba, 1 (1996), 11-38; una posible identificación dentro de la familia en idem, "Notas de oligarquía morisca granadina. La famila Ferí", Sharq Al-Andalus, 14-15 (1997-1998), 155-176.

${ }^{46}$ Bouzineb, H. y Wiegers, G., "Tetuán y la expulsión de los moriscos", Tițwān jilāl al-qarnayn 16 wa-17, Tetuán, 1996, 92-95.

47 Domínguez Ortiz y Vincent, Historia de los moriscos, 177-178.

48 En 1565, espías infiltrados descubren una red de moriscos que sacaban correligionarios de España para conducirlos a Argel o Salónica a la vez que actuaban de intermediarios entre los emigrados y los que se quedaban. Este intrincado asunto, descubierto en 1565 por espías infiltrados entre los moriscos castellanos, llega a alcanzar en su responsabilidad no 
los moriscos en Francia, mediando ante las autoridades otomanas por su seguridad y por un destino confortable y transportando a aquéllos finalmente a tierras de la Regencia de Túnez. Ya en 1608 el embajador francés en Constantinopla habla de un permiso otorgado por Enrique IV a los moriscos que, deseando viajar a Oriente, necesitaban detenerse en Marsella. Mal recibidos en Francia al principio, sus quejas a la Sublime Puerta conseguirán que un año después los testimonios se tornen en satisfacción ${ }^{49}$. La preocupación del sultán por los tránsitos de los moriscos hacia tierras musulmanas llegó a tal punto que el propio embajador otomano presenciaba los primeros embarques de granadinos desde Francia hacia Túnez ${ }^{50}$. No se trataría, con toda probabilidad, de una red que se ocupase de todos los moriscos que pudieran llegar exiliados a Francia; seguramente tenía como objetivo asegurar los destinos, en Francia, Turquía o Túnez, de unos cuantos centenares de moriscos granadinos de nombre y de posición y no tanto asegurar la suerte de toda la comunidad morisca.

Es posible que a esto último llegaran impelidos por el brusco cambio político en Francia y por la urgencia que se despertó en expulsar a los moriscos. De repente, las acciones y los contactos pensados para un grupo determinado de personas debían ampliarse para cubrir a varias decenas de miles de desterrados, con los consiguientes problemas humanos, económicos, logísticos, etc. Existían, por ende, más que evidentes divergencias entre los grupos moriscos apelotonados en los puertos franceses, divergencias provenientes ya de España y que complicaban las cosas. Si bien, como norma general, se conseguía que los más ricos costearan el pasaje de los que poco o nada tenían, muchos no estaban dispuestos a que esa fuera una regla de aplicación universal, como muestran esos moriscos castellanos que se niegan ante el comisario real a pagar el embarque a Túnez de unos moriscos granadinos alegando que son de «reinos separados» ${ }^{51}$.

sólo a los constituyentes de la compañía comercial que está en el origen de la red (tres castellanos y un granadino, quien aporta el capital), sino a arrieros moriscos que recorren buena parte de la geografía española. Fue descubierto y analizado por Tapia, S. de, "Las redes comerciales de los moriscos de Castilla la Vieja: un vehículo para sus complicidades", Studia Historica. Historia Moderna, XI (1993), 231-243; Idem, "Los moriscos de Castilla la Vieja, ¿una identidad en proceso de disolución?”, Sharq Al-Andalus, 12 (1995), 179-195.

49 "Le passage des morisques", 337.

${ }^{50}$ Lapeyre, H., Geografia de la España morisca, Valencia, 1986, 126.

${ }^{51}$ Cardaillac, L., "Procès pour abus contre les morisques en Languedoc", en Epalza y Petit, Études sur les moriscos, 103-113.

Al-Qanțara (AQ) XXIX 2, julio-diciembre 2008, pp. 307-332 ISSN 0211-3589 


\section{De nuevo en Túnez}

Si bien, como se ha señalado, el grado de información de la instalación de los moriscos en Túnez y su posterior desarrollo como comunidad es bastante alto si lo comparamos con otros países, no están todavía demasiado claros cuáles fueron los primeros pasos de la llegada morisca a la Regencia otomana. Sabemos que ya antes de la expulsión, en 1607, un centenar de moriscos granadinos encabezados por un Fernández de León llega a Túnez en un barco inglés ${ }^{52}$ y que, asimismo, los primeros desembarcos de moriscos desde Francia estaban protagonizados por moriscos de Granada, a veces mercaderes con enormes cantidades de dinero que resultaban una enorme tentación para los capitanes de los barcos. ¿Qué era lo que les llevaba allí? ¿Qué había en el vilayet de Túnez para que estos granadinos, y después miles de aragoneses y castellanos, dirigieran sus vidas hacia sus costas?

Sin duda un espacio económico y social asequible a una nueva población y unas autoridades que se mostraban dispuestas a apoyarlos; y desde luego unas promesas de compensaciones en forma de territorios, autonomía y exenciones de impuestos. Estos granadinos, que atravesaban el Mediterráneo con parte de sus fortunas a cuestas, sin duda habían consultado con Estambul ${ }^{53}$ y le habían solicitado (una solicitud más tras muchas el siglo anterior) tanto protección en sus itinerarios como un lugar seguro donde salvarse, y la emigración comenzó aún antes de que la obligara el rey Felipe III. Pero algunos datos más podrían quizá ayudar a perfilar aún más estos inicios de la presencia morisca en Túnez

Pongamos la atención en uno de los asuntos más conocidos de las primeras oleadas de moriscos arribando a Túnez: el affaire Anthoron Estienne. Éste, armador y capitán de barco de Agde, en enero de 1610 transporta con su hijo a cuarenta mercaderes moriscos granadinos y sus familias a Túnez ${ }^{54}$. Sin embargo, codicioso de las riquezas que transportan, valoradas aproximadamente en cien mil escudos de oro, Estienne maltrata a sus pasajeros y los abandona a su suerte en Porto Farina sólo con las ropas que llevaban encima. A la vuelta, el robo es

52 Epalza, "Moriscos", 258.

53 Véanse los estudios reunidos en Termimi, A., Le gouvernement ottoman et le problème morisque, Túnez, 1996.

${ }^{54}$ Cardaillac, "Procés pour abus", 103-113.

Al-Qanțara (AQ) XXIX 2, julio-diciembre 2008, pp. 307-332 ISSN 0211-3589 
descubierto, el barco retenido en el puerto y lo que resta del botín confiscado por las autoridades francesas. Por su parte, los moriscos expoliados en el viaje, entran en contacto con sus compatriotas instalados en la ciudad de Túnez y éstos presentan sus quejas en el consulado francés. Tras un proceso judicial en Montpellier, los Estienne y algunos de sus marineros serán colgados y los bienes que se pudieron recuperar devueltos a los moriscos.

A través de los documentos de presentación de queja ante el cónsul, reproducidos modernamente por Epalza ${ }^{55}$, podemos conocer los nombres de los granadinos que habían sido expoliados por el capitán francés. Un vistazo a la lista de los pasajeros expoliados y a las cantidades que cada uno alega que les han sido robadas basta para caer en la cuenta de que ese no era un embarque cualquiera. Podemos ver allí, por ejemplo y por citar a alguien que será muy conocido en Túnez años más tarde, a 'Alī b. 'Abd al-Rafí', alias Alonso Castellano ${ }^{56}$.

A petición del cónsul francés, los moriscos expoliados nombran a tres notables moriscos que representarán los intereses de sus compatriotas en el proceso en Francia, tres moriscos granadinos que venían en el barco y cuyas identidades son: Axar Abulcacim, Mahamet Sarquin y Mulay Albeihac Almariny, llamado en un segundo documento Ally ben Abdelhaq.

Evidentemente, después del título anteriormente citado de María Jesús Rubiera acerca de la familia de los Muley-Fez como príncipes meriníes emparentados asimismo con los nazaríes y, por ello, cabeza oficial de las principales familias moriscas como de hecho de toda la comunidad, el último nombre de estos representantes de los moriscos no puede ser leído como uno más. Se trata de un miembro de la prin-

55 Epalza, "Moriscos", 301-306.

${ }^{56}$ La lista de moriscos granadinos del consulado francés ayuda también, por cierto, a deshacer un entuerto. En ella aparecen dos Alonso Castellano: uno que responde al nombre árabe de «Ally Raphat» o «Aly el Rafy» (que reclama 593 escudos de oro), y un segundo identificado como «Ally Anda Raphat» o "Aly ben Abdelrafy» (que reclama 3.000 escudos). Es decir, seguramente padre e hijo en el mismo barco: el primero sería el estrecho colaborador de Abū l-Gayt al-Qaššāš en los inicios del asentamiento morisco en Túnez (ver Epalza, "Sidi Bulgayz", 152, donde Ibn Abī Lihya cita a Ibn 'Abd al-Rafî" como difunto en 1623), mientras que el segundo sería el escritor que en 1634 escribe una obra en árabe apoyando las pretensiones de los cherifes de origen andalusí (ver Gafsi-Slama, A., "Aproximación al estudio de los textos en árabe de los morisco-andalusíes en Tunisia", Sharq Al-Andalus, 12 (1995), 413-428, donde se da su nombre completo: Muhammad b. 'Abd al-Rafī‘ b. Muḥammad al-Šarīf al-Ḥusaynī al-Ŷa'farī al-Mursī al-Andalusī).

Al-Qanțara (AQ) XXIX 2, julio-diciembre 2008, pp. 307-332 ISSN 0211-3589 
cipal familia morisca de Granada (casi equivale a decir de la principal familia morisca de España), de sangre real, y que porta el mismo nombre que varios de sus antepasado 'Abd al-Haqq. Por supuesto, sigue llevando el apellido que lo liga con las casas reales de Fez y Granada, y el título de Mawlāy que delata el rango elevado de que goza entre los suyos y que conservó la familia como apellido tras su conversión al cristianismo. Dada la cantidad de dinero que reclama - 90 escudos de oro-, muy escasa en comparación con las cifras que manejan sus compañeros de barco, podríamos pensar en una persona joven, de riqueza no muy grande o simplemente de paso fugaz por Túnez.

Pero, ¿qué hace en una fecha tan temprana un miembro de la familia morisca más prestigiosa entre los suyos y entre los cristianos, en Túnez? Naturalmente es imposible que lo encontrásemos en Marruecos, que le estaba vedado a toda la familia tras la matanza de sus antepasados, pero ¿por qué abandonar Granada, donde podían gozar de un destino más o menos benévolo y donde, de hecho, tienen los $\mathrm{Mu}-$ ley-Fez una posición de realce durante todo el siglo XVI? ¿Es este misterioso al-Marīnī, que no vuelve a aparecer en la documentación del consulado, el primer jefe de los andalusíes en Túnez, contemporáneo de Luis Zapata y antecesor de Mustafá de Cárdenas?

¿Y para quiénes se funda la madrasa de los andalusíes en 1625 ? Desde luego, puede afirmarse con una cierta probabilidad que esos estudiantes no serían los moriscos aragoneses y castellanos que van llegando a partir de 1610, totalmente ignorantes de la lengua árabe y para los que hay que articular una enseñanza en español ${ }^{57}$. Reveladora es asimismo la inscripción de la madrasa, donde se cita entre sus fundadores al šarîf Muhammad b. Maḥfüz, šayj de Testur, de ascendente andalusí, y a un Ảbū l-Ḥasan 'Alī b. 'Alī 'Abd Allāh Muhammad al-Niwālī, conocido como Ibn al-Sarrāŷ, como naqūb al-šurafă' al-andalusiyyin o representante de los nobles chorfa (familias descendientes del Profeta) provenientes de al-Andalus ${ }^{58}$. ¿Quién es este noble Abencerraje que parece ocupar un lugar de importancia en Túnez y que, él mismo o un descendiente, parece haber protegido a los moriscos de alto

57 Bernabé Pons, L.F., "La literatura en español de los moriscos en Túnez", IX Simposio Internacional de Mudejarismo. Actas, Teruel, 2004, 449-464.

58 Ver reproducción de la inscripción fundacional en Gafsi, A., "La médersa des moriscos andalous a Tunis", Sharq Al-Andalus, 5 (1988), 169-182 (173). 
nivel cultural ${ }^{59}$, en árabe y en castellano? ¿Y qué papel juegan estos cherifes andalusíes, que parecen haber formado un grupo muy cerrado en Túnez ${ }^{60} \mathrm{y}$ entre los que podemos contar, aparte del anterior, a los ya citados granadinos Muhammad b. 'Abd al-Rafí' (alias Alonso Castellano) ${ }^{61} \mathrm{o}$ al propio Mustafá de Cárdenas, el jeque de los andalusíes ${ }^{62}$, en la vertebración del grupo morisco andalusí y en su relación con las autoridades otomanas de Estambul, visitada por varios de estos personajes en viajes de ida y vuelta desde Túnez? En un notable trabajo ${ }^{63}$ habla Gerard Wiegers de la forja de una «Maghribi-Morisco identity» en el norte de África y en Túnez en particular, al hilo de fenómenos como las polémicas anticristianas de los moriscos o precisamente la creación de la Madrasat al-Fath. Posiblemente, tiene razón al vislumbrar esa identidad que va surgiendo, aunque quizá haya que ver exactamente de qué distintos elementos está compuesta.

Los interrogantes que se plantean son muchos, desde luego superiores a las respuestas que por ahora podemos tener y, en cualquier caso, mucho más allá del espacio permisible para estas páginas. Los indicios que tenemos nos sugieren una temprana instalación de personajes granadinos notables, por familia o por riqueza, en Túnez. Conscientes de que el futuro era cada vez menos halagüeño para los suyos y seguramente guiados por las autoridades turcas, una serie de destacados moriscos granadinos se desplazan en fecha temprana a Túnez, donde posiblemente encontrarían a algunos cherifes de más o menos lejano origen andalusí. De acuerdo con el dey 'Uțmān y con Estambul, comienzan a traer a Túnez a otros moriscos granadinos que habían salido también tempranamente de España vía Francia conservan-

${ }^{59}$ El cherife 'Alī al-Niwālī Ibn Sarrāŷ, administrador de las rentas del dey Yūsuf, es el destinatario de la polémica anticristiana del morisco Taybilī y asimismo pide a Muhammad Ibn 'Abd al-Rafì', que componga su obra Al-anwār an-nabawiyya fì abā jayr al-barriyya sobre la línea genealógica de Muhammad, sus compañeros y descendientes dentro de la reivindicación de la preeminencia de la genealogía de los cherifes de origen español en esa nobleza religiosa que tenía su centro en Túnez: Gafsi, "Aproximación”, 421-423.

${ }^{60}$ Epalza, "Moriscos", 296-297.

${ }^{61}$ Turki, A., "Documents sur le dernier exode des andalous vers la Tunisie", en Epalza y Petit, Études sur les moriscos, 114-127.

${ }_{62}$ Su hijo es conocido por Sīdī al-Šrinf: Epalza, "Moriscos", 264, 283, 289.

${ }^{63}$ Wiegers, G., "European converts to Islam in the Maghrib and the polemical writings of the Moriscos", en M. García-Arenal (ed.), Conversions islamiques/Islamic Conversions (Identités religieuses en Islam méditerranéen/Religious Identities in Mediterranean Islam), París, 2001, 207-223.

Al-Qanțara (AQ) XXIX 2, julio-diciembre 2008, pp. 307-332 ISSN 0211-3589 
do sus riquezas, y que encontrarían el apoyo de un personaje espiritual y socialmente muy importante como Abū 1-Gayt al-Qaššāš. A éstos más tarde se unirían a la fuerza los miles de aragoneses que, la mayoría sin recursos, languidecían en los puertos franceses y cuya llegada masiva pudo provocar que el dey Yūsuf (1610-1637) revocara los privilegios fiscales y legales que su antecesor 'Utmān les había otorgado, quizá pensando únicamente en una emigración más reducida. No hay que olvidar que varios de los barcos que venían de Francia iban también cargados con pólvora y armas y, posiblemente, al nuevo y desconfiado dey no le resultaba atractivo contar en sus dominios con un grupo acogido, sí, pero también rico, cohesionado y armado.

Todo este conjunto de noticias reclama mayor investigación en torno a lo que fue el Túnez de los primeros años del siglo XVII y acerca de las primeras implantaciones de moriscos en la Regencia turca. Si esta hipótesis pudiese cobrar sustento, Túnez habría sido concebida por personajes destacados de los moriscos granadinos como una «nueva Granada» en la que proseguir más tranquilamente una vida que en estos años se mostraba turbulenta por el antiguo reino nazarí. Algunos topónimos tunecinos, como Granadella en la desembocadura del río Medjerda ${ }^{64}$, Gurnāta cerca de El-Alia o Granada como barrio de Testur ${ }^{65}$, podrían ser testimonio toponímico de ese propósito primitivo. Los primeros moriscos allí instalados habrían actuado como cabeza de puente para los demás, preparando el terreno de una emigración de mayor calibre desde los puertos de Francia y colocando allí a uno de sus caballeros más oficiales. Estos moriscos granadinos habrían de ser los que se entendieran con las autoridades y personajes principales de la Regencia: su rango, sus riquezas, sus contactos con Estambul y, especialmente, su lengua los hacían idóneos para tratar con las capas altas de la sociedad tunecina, inalcanzable para los moriscos hispanohablantes que llegarían posteriormente.

La comunidad morisca atraviesa un período enormemente crítico en los primeros veinte años del siglo XVII. Las persecuciones en España y la expulsión postrera supusieron durísimas pruebas que muchos

${ }^{64}$ Epalza, M. de, "Nuevos documentos sobre descendientes de moriscos en Túnez en el siglo XVIII", Studia Historica et Philologica in Honorem M. Batllori, Roma, 1984, 195-228.

${ }^{65}$ Daoulatli, A., "Inscription à la mosquee andalouse d'El-'Aliya", en Epalza y Petit, Études sur les moriscos, 285-290; Latham, "Towards a study”, 54 (de la traducción francesa).

Al-Qanțara (AQ) XXIX 2, julio-diciembre 2008, pp. 307-332 ISSN 0211-3589 
no pudieron superar. Frente a ellas, algunos grupos de moriscos opusieron en la medida de lo posible sus distintos grados de cohesión, sus modos de organización y la ayuda de ocasionales colaboradores. Si en distintos lugares de la Península se había procurado en el siglo XVI una resistencia intelectual ante la opresión cristiana, a comienzos del siglo XVII fueron las redes comerciales y humanas de los moriscos, en España y fuera de ella, las que se pusieron en marcha. Y dentro de estas redes se encuentran muchas veces moriscos granadinos que se ponen a la cabeza de los exiliados.

Túnez parece ser uno de estos casos en los que se intenta desplazar con el menor perjuicio posible a toda una comunidad más o menos cohesionada. A juzgar por las riquezas que muchos moriscos llevaban en los barcos, o por la fortuna que varios de ellos llegaron a atesorar en la Regencia otomana, el éxito coronó buena parte de sus operaciones, hasta el punto de despertar la alarma del dey Yūsuf. Un documento también de Simancas y publicado por la CODOIN ${ }^{66}$ nos cita un memorial que un morisco ha elevado al visir en Constantinopla en septiembre de 1612. En él, tras hablar de los desmanes sufridos por los moriscos en España a manos de los cristianos, se queja precisamente de que el dey les haya quitado las libertades de la gente de guerra en Túnez, de las que gozaban desde los tiempos de 'Uțmān. Solicita que se las confirmen permanentemente y que reciba en la milicia y pagas a los moros, no sólo como provecho político, sino también religioso. El morisco pedía cosas muy concretas para el bienestar de su comunidad, aunque no podía imaginar que el chauz ${ }^{67}$ que traía ese memorial a Túnez desde Estambul iba a hacer primero un alto con el duque de Osuna, a quien seguramente servía como espía. El duque, tras conocer al memorial, lo envía al rey con el comentario: «[el memorial] envío sólo a fin de que V. M. pueda mandar ver lo que cada día la experiencia muestra de cuan acertada resolución fue el haber mandado V. M. echar esta gente de España».

Recibido: $25 / 10 / 06$

Aceptado: 07/06/07

66 AGS, Leg. 1166; CODOIN, t. XLV, doc. CCXI.

${ }^{67}$ Para la figura del chauz como funcionario enviado del sultán o visir y encargado de hacer ejecutar las órdenes ver $E I^{2}$, Mantran, R., "Ča'ush".

Al-Qanțara (AQ) XXIX 2, julio-diciembre 2008, pp. 307-332 ISSN 0211-3589 